\title{
Injury Reporting in Collegiate Soccer Players and the Impact of Non-Reporting
}

Nathaniel W. Nelson

Chestnut Hill College, natenelson.nyc@gmail.com

Carolyn Albright

Chestnut Hill College, albrightc@chc.edu

Follow this and additional works at: https://nsuworks.nova.edu/ijahsp

Part of the Medicine and Health Sciences Commons

\section{Recommended Citation}

Nelson NW, Albright C. Injury Reporting in Collegiate Soccer Players and the Impact of Non-Reporting. The Internet Journal of Allied Health Sciences and Practice. 2020 Jan 01;18(4), Article 19.

This Manuscript is brought to you for free and open access by the College of Health Care Sciences at NSUWorks. It has been accepted for inclusion in Internet Journal of Allied Health Sciences and Practice by an authorized editor of NSUWorks. For more information, please contact nsuworks@nova.edu. 


\title{
Injury Reporting in Collegiate Soccer Players and the Impact of Non-Reporting
}

\begin{abstract}
Purpose: The purpose of this study was to determine injury reporting rates of collegiate soccer players and explore possible consequences of not reporting these injuries. Methods: Soccer players (male and female) from eight Division II and III schools were surveyed about their injury history during college, injury reporting behavior, and the consequences of their worst non-reported injury. The head coach of each soccer team was also surveyed about their perception of player injury reporting on their team. Results: Of the 232 athletes surveyed, 171 had been injured during their college career and $67(39.2 \%$ of those injured, $28.8 \%$ of all surveyed) had not reported one of their injuries at some point during their college career. Coaches perceived that the rate of non-reporting on their team would be on average $16.6 \%$. Eightyseven percent of non-reporters reported that due to their injury they had to lower intensity of playing, $20.9 \%$ missed playing/practice time, and $92.5 \%$ self-treated while they were injured. $43.3 \%$ percent were re-injured and 12 of those athletes missed more time because of the re-injury. $59.7 \%$ percent would choose to not report an injury again. Conclusion: Approximately $40 \%$ of all soccer players who had been injured during their collegiate career sustained an injury that they did not report. This unreported injury in many cases led to negative consequences such as decreased intensity of play or re-injury. College athletic trainers and coaches must be aware of this non-reporting and determine the best practice for creating a better environment for openness about injury discussion and reporting.
\end{abstract}

\section{Author Bio(s)}

Nathaniel W. Nelson, B.S, is a Physical Therapy Aid at Martha Jefferson Hospital in Charlottesville, VA. He is a recent graduate from Chestnut Hill College.

Carolyn Albright, PhD., is the Department Chair of the Health and Exercise Science Department at Chestnut Hill College. She is a certified Exercise Physiologist 


\title{
TIIAHSP \\ The Internet Joumnal of Allied Health Sciences and Practice \\ Dedicated to allied health professional practice and education \\ Vol. 18 No. 4 ISSN 1540-580X
}

\section{Injury Reporting in Collegiate Soccer Players and the Impact of Non-Reporting}

\author{
Nathaniel W. Nelson \\ Carolyn Albright \\ Chestnut Hill College \\ United States
}

\begin{abstract}
Purpose: The purpose of this study was to determine injury reporting rates of collegiate soccer players and explore possible consequences of not reporting these injuries. Methods: Soccer players (male and female) from eight Division II and III schools were surveyed about their injury history during college, injury reporting behavior, and the consequences of their worst non-reported injury. The head coach of each soccer team was also surveyed about their perception of player injury reporting on their team. Results: Of the 232 athletes surveyed, 171 had been injured during their college career and 67 ( $39.2 \%$ of those injured, $28.8 \%$ of all surveyed) had not reported one of their injuries at some point during their college career. Coaches perceived that the rate of non-reporting on their team would be on average $16.6 \%$. Eighty-seven percent of non-reporters had to lower intensity of playing due to their injury, $20.9 \%$ missed playing/practice time, and $92.5 \%$ self-treated while they were injured. Re-injuries occurred in $43.3 \%$ percent of athletes and 12 of those athletes missed more time because of the re-injury. Those who would choose to not report an injury again accounted for $59.7 \%$ of athletes in this study. Conclusion: Approximately $40 \%$ of all soccer players who had been injured during their collegiate career sustained an injury that they did not report. This unreported injury in many cases led to negative consequences such as decreased intensity of play or re-injury. College athletic trainers and coaches must be aware of this non-reporting and determine the best practice for creating a better environment for openness about injury discussion and reporting.
\end{abstract}




\section{INTRODUCTION}

Injury rates during collegiate sports are high. Hootman et al reported approximately 182,000 injuries during the 1988/1989 to 2003/2004 national college athletic seasons. ${ }^{1}$ The data also show that most injuries occur during pre-season practice compared to in-season practice, and more injuries occur during games as compared to during practice. Agel et al reported that from the 19882003 collegiate soccer seasons, men sustained 6,693 injuries during approximately 22,000 games and 6,281 injuries during approximately 62,000 practices. ${ }^{2}$ Similar reports, but slightly lower rates, were provided by Dick et al for female collegiate soccer players, with 5,373 injuries during approximately 20,000 games and 5,836 injuries over more than 54,000 practices being reported over the same 15 -year time period. ${ }^{3}$

While data could not be found on non-reporting of orthopedic injuries, $51 \%$ of collegiate athletes surveyed at a Division I college did not report their concussion in a timely manner. ${ }^{4}$ A 2013 study which surveyed high school athletes found that out of 84 concussions, only $48.8 \%$ were reported to their coach or medical professional. ${ }^{5}$ Rivara et al also reported that $69 \%$ of high school athletes in football and women's soccer play with concussion symptoms, while only $40 \%$ stated their coach knew of the concussion. ${ }^{6}$

The physical risks of not reporting injuries can be detrimental to a player's career. Re-injuries make up 8-19\% of total injuries in sport. ${ }^{7-9} \mathrm{~A}$ study by Hallan and Ekstrand found that in professional European football players, the biggest risk factor for hamstring injury is the history of a hamstring injury. ${ }^{11}$ And in the previously discussed Asken 2016 study, athletes that did not report their concussion in a timely manner, missed more playing time, and needed a longer recovery period compared to athletes who did report their symptoms immediately.

Knowing the high injury rates in collegiate soccer and the potential for athletes to not report their injuries, the purpose of this study was to determine the extent to which collegiate soccer players do not report their injuries and to discover the repercussions of not reporting these injuries. Secondarily, we also sought to find out the coach's perception of injury reporting on his/her team and analyze whether the perceived reporting rate and actual reporting rates were similar.

\section{METHODOLOGY \\ Subjects}

Surveys were given to current male and female collegiate soccer players over the age of 18 . Athletes were from Division II and III colleges in the mid-Atlantic area of the U.S. Athletes were excluded from the analysis if they were under the age of 18 or had no history of injury during their collegiate soccer career. The head soccer coach of each respective team was also given a 1 question survey. All participants signed an informed consent prior to participation and the study was approved by the college's Internal Review Board.

\section{Instrumentation}

The survey provided to the athletes included basic descriptors such as gender, year in school, college athletic division, and whether the athlete was a starter on the team. All players attending the practice or meeting were given a survey. The first injury related question asked whether the athlete had ever been injured during their college career. This method of providing a survey to all players on the team was chosen so that all players had a survey given to them in front of their team members to aid in keeping their injury history private to others in the room. For this question, if a player answered no, then the individual did not go any further in the survey. If they answered yes, then they were prompted to continue. The next question then asked the individual if they had ever sustained an injury they did not report to a coach or athletic trainer. If an athlete noted that they had an injury they did not report, they were then prompted to answer additional questions regarding the most severe injury they had sustained but did not report (in case the athlete had not reported more than one injury). These additional questions included the perceived severity of the injury (1-5 Likert scale), yes or no questions regarding consequences of playing with the injury (did they miss playing/practice time and was their play affected), if they self-treated, were they reinjured, and whether they would not report an injury again. Questions were administered in paper format. Coaches were also asked separately what percentage of athletes on their team did they believe at any point sustained an injury but did not report the injury to either the coaches or athletic trainers.

\section{Survey Administration}

All surveys were administered during the spring playing season. The survey was administered to the whole team, either after a practice or during a team meeting. The coach was not in the room at the time of the survey and did not provide specific information about the survey to the athletes prior to administration.

Coaches were spoken to separately outside of the room where the players were located. The coaches were asked what percentage of athletes who are on the team did they believe did not report an injury at some point during their years playing for them. 


\section{Statistical Procedures}

All statistics were run on IBM Statistics SPSS 24. Descriptive analysis was used for all survey questions. Independent t-tests were performed to analyze if differences existed between injury severity and whether an athlete was reinjured, and whether the average minutes an athlete plays per game and school year differed among athletes that did and did not report their injury.

\section{RESULTS}

Of the 232 soccer players surveyed, 171 of these players had sustained an injury during their college career. Of the athletes who had an injury, 128 were male and 43 were female. There were 84 Division II and 87 Division III athletes, and the breakdown per year in school was 52 freshmen, 52 sophomores, 50 juniors, and 17 seniors. Of the 171 soccer players who had been injured, 67 (39.2\% of all injured, $28.8 \%$ of all surveyed) of the athletes had an injury they did not report. All injured participant characteristics are shown in Table 1.

TABLE 1. Characteristics of all Injured Athletes $(n=171)$

\begin{tabular}{|l|c|}
\hline & \# Athletes \\
\hline Male & $128(74.9 \%)$ \\
\hline Female & $43(25.1 \%)$ \\
\hline Division II & $84(49.1 \%)$ \\
\hline Division III & $87(50.9 \%)$ \\
\hline Freshman & $52(30.2 \%)$ \\
\hline Sophomore & $52(30.2 \%)$ \\
\hline Junior & $50(29.2 \%)$ \\
\hline Senior & $17(9.9 \%)$ \\
\hline Starter & $87(50.9 \%)$ \\
\hline
\end{tabular}

A greater percentage of injured female athletes $(46.5 \%)$ did not report an injury to a coach or athletic trainer compared to male athletes (36.7\%). A greater percentage of Division II athletes (42.9\%) did not report an injury to a coach or athletic trainer compared to Division III athletes (35.6\%). Characteristics of all non-reporting athletes can be found in Table 2. Coaches, on average, believed their team's rate of non-reporting to be $16.6 \%$. The actual rate of non-reporting was $28.8 \%$ (Table 3 ). Coaches of male teams felt that fewer students did not report injuries $(17.9 \%)$ compared to the actual number $(20.3 \%)$, whereas coaches of female teams thought more athletes were not reporting injuries (13.3\%) compared to the actual non-reporting rate (8.6\%) (Table 4).

TABLE 2. Characteristics of all Non-Reporting Athletes $(n=67)$

\begin{tabular}{|l|c|c|c|}
\hline & \# Athletes & \% Non-Reporters & $\%$ All Injured \\
\hline Male & 47 & $70.1 \%$ & $36.7 \%$ \\
\hline Female & 20 & $29.9 \%$ & $46.5 \%$ \\
\hline Division II & 36 & $53.7 \%$ & $42.9 \%$ \\
\hline Division III & 31 & $46.3 \%$ & $35.6 \%$ \\
\hline Freshman & 20 & $29.9 \%$ & $38.5 \%$ \\
\hline Sophomore & 20 & $29.9 \%$ & $38.5 \%$ \\
\hline Junior & 22 & $32.8 \%$ & $44.0 \%$ \\
\hline Senior & 5 & $7.5 \%$ & $29.4 \%$ \\
\hline Starter & 40 & $59.7 \%$ & $46.0 \%$ \\
\hline
\end{tabular}

TABLE 3. Coaches Perceived Rate of Not Reporting Against Actual Rate of Not Reporting

\begin{tabular}{|l|c|c|c|}
\hline & Avg. $\%$ Coaches & \% Actual Not Reporting & Avg. Difference \\
\hline Male & $17.9 \%$ & $20.3 \%$ & $-2.4 \%$ \\
\hline Female & $13.3 \%$ & $8.6 \%$ & $4.7 \%$ \\
\hline Division II & $23.6 \%$ & $35 \%$ & $-11.4 \%$ \\
\hline Division III & $10.8 \%$ & $13.3 \%$ & $-2.5 \%$ \\
\hline All & $16.6 \%$ & $28.8 \%$ & $-12.2 \%$ \\
\hline
\end{tabular}

${ }^{*}$ number of athletes non-reporting/all 232 athletes initially given surveys 
Eighty-seven percent of athletes who did not report an injury had to lower intensity of play, $40 \%$ missed playing time during either game or practice, and $33 \%$ self-treated while they were injured. Forty-four percent $(n=12)$ of athletes that did not report their injury were re-injured, and $50 \%$ of those missed more time because of re-injury. Fifty-six percent of injured athletes who did not report would choose to not report an injury again.

TABLE 4. Consequences of Not Reporting Injury $(n=67)$

\begin{tabular}{|l|c|c|}
\hline Self- treated injury & Yes & No \\
\hline Missed practice/playing time & $51(93 \%)$ & $4(7 \%)$ \\
\hline Affected play & $22(40 \%)$ & $33(60 \%)$ \\
\hline Had to lower intensity of activity & $20(60 \%)$ & $13(40 \%)$ \\
\hline Resulted in re-injury & $48(87 \%)$ & $6(11 \%)$ \\
\hline Missed additional time due to re-injury & $24(44 \%)$ & $30(55 \%)$ \\
\hline Would not report an injury again & $12(50 \%)$ & $12(50 \%)$ \\
\hline
\end{tabular}

A t-test showed no statistical differences $(p=0.219)$ between athletes that were and were not reinjured and the initial injury severity. Additional analyses did not reveal any statistically significant differences between athletes that did and did not report their injury and playing time (average minutes played per game) $(\mathrm{p}=0.217)$ or school year $(\mathrm{p}=0.961)$.

\section{DISCUSSION}

Reporting rates for athletes and concussions has more recently been addressed; however, reporting rates for general orthopedic injuries in college athletes has not been researched. This study aimed to answer how many athletes are not reporting injuries and what the repercussions of that non-reporting may be. One hundred seventy-one of the collegiate soccer players that were surveyed were injured at least once during their college career. Of that 171 respondants, 67 college soccer players did not report one of these injuries.

This non-reporting rate, $39 \%$ of injured college soccer players, is not far off from the most recently reported concussion reporting rates. Register-Mihalik et al reported that only $48.8 \%$ of high school athletes that sustained a concussion reported their condition (51.2\% did not report). ${ }^{5}$ Similarly, Rivara et al found that only $40 \%$ of high school football and soccer players reported their concussion to their coach or medical professional, $60 \%$ did not report their concussion or symptoms. ${ }^{6}$

The current study did not investigate reasons why an athlete chose not to report an injury. Previous research shows that the likelihood of an athlete reporting their concussion had been largely determined by the perceived coach's support of the athlete. ${ }^{11}$ Older athletes who had been on the team longer perceived less support from their coach, and would be less likely to think that telling their coach they had a concussion was the right decision. ${ }^{11}$ Chrisman et al also sought to determine the reasons for athletes not reporting concussions to their coaches..$^{12}$ The study found that lack of concussion knowledge was not a reason for not reporting; in other words, athletes knew the symptoms and dangers of a concussion. However, these athletes reported that reasons for not reporting their concussion included not wanting to be taken out of play, not wanting to look weak to their teammates or coaches, difficulty in determining whether the injury symptoms are severe enough to stop playing, and that they felt their coach was not approachable when it came to discussing injury or pain.

These previous findings point toward the opportunity for the coach to have a significant impact on increasing reporting rates. Our study found that coaches under-predicted the rate of not reporting for all team members on average by $12.2 \%$, and that $39.2 \%$ of all injured athletes did not report an injury. This data shows an obvious disconnect between athletes and coaches when it comes to injury reporting. Most coaches surveyed in our study brought up their "open door policy" and how effective it was. These were often the teams with the largest difference between perceived and actual rate of reporting. Both coaches and athletic trainers need to be more aware of the injury reporting issues that may be prevalent on their teams.

The athletes in our study reported repercussions from the injuries they did not report, including having to lower the intensity of their play, missing playing time, and ultimately affecting their overall quality of play. A study of college athletes showed that $51 \%$ did not report their concussions immediately and those that did not report in a timely manner added an average of 4.9 extra missed days of play to their recovery time compared to those that properly reported their concussion. ${ }^{4}$

Regarding repercussions of non-reporting, $44 \%$ of athletes that did not report their injury became re-injured after not properly addressing the injury the first time. Injury data has shown that re-injuries make up 9-19\% of all injuries in sport.-10 Even with all of 
the negative repercussions of not reporting an injury, including re-injury and decreased quality of play, $56 \%$ of all athletes that did not report their injury said they would not report an injury again.

There were some limitations in this study. There were fewer seniors surveyed because all teams were surveyed during the spring season when most seniors are no longer active with their team. The addition of more tenured players on the team filling out the survey could influence the overall reporting rate statistics as well as repercussions. The survey was also administered to fewer female teams than males due to response rates from coaches. Gender differences as well as coach/athlete gender difference were not analyzed. The survey also did not distinguish exact injury type or location, such as lower versus upper body.

The current study showed a high injury non-reporting rate for college soccer players, one that should be of alarm to collegiate teams and support staff. Coaches and collegiate sport medicine professionals need to analyze the relationships with their athletes as well as team dynamics to possibly create a better environment for injury reporting on their teams. Future research on gender correlations for non-reporting, as well as coach/athlete gender differences for non-reporting, is needed for the future of developing medical reporting best practices. Also, a more in depth look at why college athletes are choosing not to report orthopedic injuries may help with the development of injury reporting procedures.

\section{REFERENCES}

1. Hootman JM, Dick R, Agel J. Epidemiology of collegiate injuries for 15 sports: summary and recommendations for Injury prevention initiatives. J Athl Train. 2007; 42(2):311-319. [PMID:17710181]

2. Agel J, Evans TA, Dick R, Putukian M, Marshall SW. Descriptive epidemiology of collegiate men's soccer injuries: National Collegiate Athletic Association Injury Surveillance System, 1988-1989 through 2002-2003. J Athl Train. 2007; 42(2):270-277. [PMID:17710176]

3. Dick R, Putukian M, Agel J, Evans TA, Marshall SW. Descriptive epidemiology of collegiate women's soccer injuries: National Collegiate Athletic Association Injury Surveillance System, 1988-1989 through 2002-2003. J Athl Train. 2007;42(2):278-285.

[PMID:17710177]

4. Asken BM, McCrea MA, Clugston JR, Snyder AR, Houck ZM, Bauer RM. "Playing through it": delayed reporting and removal from athletic activity after concussion predicts prolonged recovery. J Athl Train. 2016;51(4):329-335. [PMID:27111584]

5. Register-Mihalik JK, Guskiewics KM, McLeod TCV, Linnan LA, Mueller FO, Marshall SW. Knowledge, attitude, and concussion-reporting behaviors among high school athletes: a preliminary study. J Athl Train. 2013;48(5):645-653. [PMID:23848520]

6. Rivara FP, Schiff MA, Chrisman SP, Chung SK, Ellenbogen RG, Herring SA. The effect of coach education on reporting of concussions among high school athletes after passage of a concussion law. Am J Sports Med. 2014;42(5):1197-1203.

[PMID:24569704]

7.Bird YN, Waller AE, Marshall SW, Alsop JC, Chalmers DJ, Gerrard DF. The New Zealand Rugby injury and performance project: V. Epidemiology of a season of rugby injury. Br J Sports Med. 1998;32(4);319-325. [PMID:9865405]

8. Faude $\mathrm{O}$, Junge A, Kindermann W, Dvorak J. Injuries in female soccer players a prospective study in the German national league. Am J Sports Med. 2005;33(11):1694-1700. [PMID:16093546]

9. Melegati G, Tornese D, Gevi M, Trabattoni A, Pozzi G, Schonhuber H, Volpi P. Reducing muscle injuries and reinjuries in one Italian professional male soccer team. Muscles Ligaments Tendons J. 2013;3(4):324-330. [PMID:24596697]

10. Hallén A, Ekstrand J. Return to play following muscle injuries in professional footballers. J Sports Sci. 2014;32(13):12291236. [PMID:24784885]

11. Baugh CM, Kroshus E, Daneshvar DH, Stern RA. Perceived coach support and concussion symptom-reporting: differences between freshmen and non-freshmen college football players. J Law Med Ethics. 2014;42(3):314-322. [PMID:25264089] 
12. Chrisman SP, Quitquit C, Rivara FP. Qualitative study of barriers to concussive symptom reporting in high school athletics. J Adolesc Health. 2013;52:330-335. [PMID:23427783] 